Chapter 4

\title{
Multiscale X-Ray Scattering for Probing Chemo- Morphological Coupling in Pore-to-Field and Process Scale Energy and Environmental Applications
}

\author{
Greeshma Gadikota \\ Additional information is available at the end of the chapter
}

http://dx.doi.org/10.5772/intechopen.76266

\begin{abstract}
One of the greatest challenges of our generation is the sustainable storage of environmentally harmful by-products of energy production processes. High-level nuclear wastes and $\mathrm{CO}_{2}$ produced from the energy sectors are examples of these by-products. To ensure the environmentally benign storage of these by-products in a solid form, it is essential to understand the chemical and morphological features of the materials in which these byproducts are immobilized. With recent advancements in X-ray scattering, it is now possible to map the structure and the microstructure of architected and natural materials across four decades in spatial scale. Multiscale X-ray scattering that encompasses ultrasmall-, small-, and wide-angle X-ray scattering (USAXS/SAXS/WAXS) allows us to probe material features in the spatial ranges of $\sim 5 \mu \mathrm{m}-10 \mathrm{~nm}, \sim 100-1 \mathrm{~nm}$, and $\sim 1 \mathrm{~nm}-0.2 \AA$, respectively. This connection is illustrated using two specific examples. The first example involves determination of the changes in the porosity and the structure of beidellite, a swelling clay used in the repository design for nuclear waste disposal, on heating to temperatures above $1000^{\circ} \mathrm{C}$. The second example illustrates the changes in the nanoscale porosity of heat-treated serpentine after reacting with $\mathrm{CO}_{2}$ to form magnesium carbonate.
\end{abstract}

Keywords: X-ray scattering, porous materials, structural and microstructural changes, hierarchical materials, materials for acid gas storage, contaminant removal

\section{Introduction}

Developing technological solutions for the long-term and sustainable storage of environmentally harmful by-products of energy production processes is one of the critical needs of our society. Examples of these by-products include high-level nuclear wastes and $\mathrm{CO}_{2}$ produced from the 
energy or industrial sectors. A fundamental understanding of the chemo-morphological coupling in materials containing these immobilized environmentally hazardous by-products is essential for predicting the long-term fate of these contaminants. In this context, chemo-morphological coupling refers to the influence of structural changes in materials at the sub-nanoscale on the nano- and mesoscale morphological changes in materials. Understanding chemo-morphological connectivity in materials allows for establishing a fundamental basis for the bulk-scale properties such as the extent of contaminants immobilized in the solid matrix. The recent development of multiscale $\mathrm{X}$-ray scattering techniques presents a non-invasive, reliable, and robust approach for probing the changes in the structure and morphology of materials from the atomicto-micrometer scales.

Multiscale X-ray scattering encompasses ultrasmall-, small-, and wide-angle X-ray scattering (USAXS/SAXS/WAXS) measurements. USAXS, SAXS, and WAXS measurements provide a spatial resolution in the range of $\sim 5 \mu \mathrm{m}-10 \mathrm{~nm}, 100-1 \mathrm{~nm}$, and $1 \mathrm{~nm}-0.2 \AA$, respectively. The four decades of spatial scale can be probed in a single measurement within a span of 3-4 min. The capability of connecting microstructural and structural changes using in-operando measurements during reaction-inducing events is less than 5 years old [1]. This capability is an extension of the application of ex-situ SAXS measurements to determine the microstructural features of porous materials such as coals [2-7], sedimentary rocks [8], and igneous rocks [9-11]. Other studies quantified the porosity in limestone and sandstone using ultra-small and small angle neutron scattering (USANS/SANS) measurements supported by complimentary electron microscopy imaging $[12,13]$. With the recent interest in energy recovery from unconventional formations, the non-invasive characterization of the porosity in shales [14-16] and its constituents such as clays [17-19] using USAXS/SAXS has received increased attention.

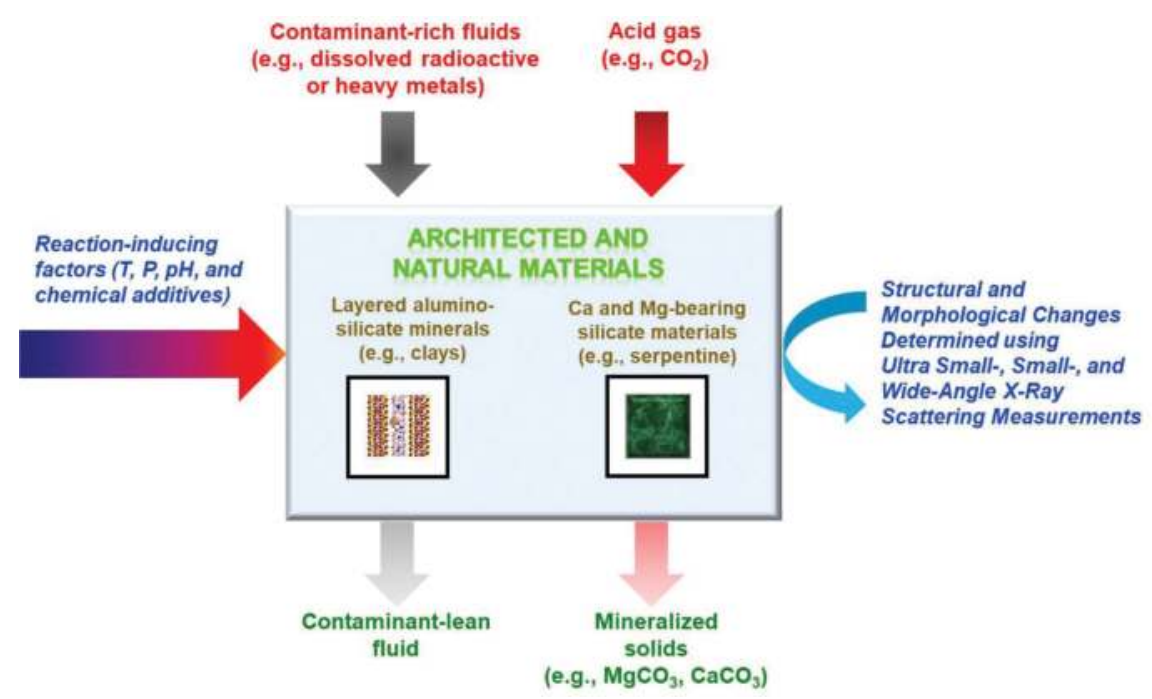

Figure 1. Sustainable energy and environmental applications probed using ultrasmall-, small-, and wide-angle X-ray scattering measurements. 
One of the advantages of multiscale X-ray scattering is the ability to probe, in-operando, the dynamic changes across the material hierarchy. This approach is illustrated by following the dynamic morphological and structural changes during the heat treatment of beidellite, a swelling clay with a hierarchical material structure. Beidellite, a swelling clay is used in the repository design for nuclear waste disposal and for developing catalytically active materials for clean energy production [20]. Beidellite is the aluminum-rich member of the montmorillonitebeidellite series of minerals [21]. Another example illustrates the reduction in the porosity of heat-treated serpentine on reaction with $\mathrm{CO}_{2}$ to form magnesium carbonate for the permanent storage of $\mathrm{CO}_{2}$. These specific examples illustrate the application of multiscale $\mathrm{X}$-ray scattering techniques for probing material transformations at the crystal structural and pore-scale levels for field and process scale applications in energy and environment, as shown in Figure 1.

\section{Analyses of ultrasmall and small angle scattering data for porous materials}

Given the multiscale nature of the applications described in the previous section, powerful techniques such as ultra-small, small, and wide-angle X-ray scattering (USAXS/SAXS/WAXS) are needed to probe the structures of materials across scales. At the angstrom scale, wide angle X-ray scattering (WAXS) provides detailed insights into the internal structure of crystalline materials by modeling the Bragg diffraction peaks. At the nanometer scale, small angle X-ray scattering (SAXS) provides quantitative information regarding the shape and size of the scattering objects including the relative roughness of pore-solid interfaces in porous materials. By combining small angle X-ray scattering (SAXS) with ultra-small angle X-ray scattering (USAXS), it is now possible to quantify the particle and pore sizes across the material hierarchy in architected materials or the fractal morphology in heterogeneous materials from the nanometer to millimeter scale. The key relationships for quantifying the microstructures in materials using small angle scattering are discussed in the following paragraphs.

The measured scattering, $I(\mathbf{Q})$ is related to the spatial distribution of the coherent X-ray or neutron scattering length density, $\rho(\mathbf{r})$ over the sampling volume, $V_{\mathrm{S}}$ using the following expression: [22-24]

$$
I(\mathbf{Q})=\frac{\mathrm{d} \Sigma}{\mathrm{d} \Omega}(\mathbf{Q})=\frac{1}{V_{\mathrm{S}}}\left|\int_{V_{\mathrm{S}}} \rho(\mathbf{r}) \exp (i \mathbf{Q} \cdot \mathbf{r}) \mathrm{d}^{3} \mathbf{r}\right|^{2}
$$

Simplification of Eq. (1) by assuming that the isotropic microstructure consists of scattering particles or features of number density, $n_{\mathrm{P}}$ (i.e., volume fraction, $\Phi_{\mathrm{V}}=n_{\mathrm{P}} V_{\mathrm{P}}$ ) yields Eq. (2) where $|\Delta \rho|^{2}, \gamma_{0}(r), V_{\mathrm{P}^{\prime}} F_{\mathrm{P}}{ }^{2}(Q)$, and $S_{\mathrm{p}}(Q)$ represent the scattering contrast factor, the dimensionless atomic pair correlation function, the individual scattering feature volume, feature form-factor, and the interparticle structure factor, respectively.

$$
I(Q)=\frac{\mathrm{d} \Sigma}{\mathrm{d} \Omega}(Q)=n_{\mathrm{P}}\lfloor\Delta \rho\rfloor^{2} V_{\mathrm{P}} \int_{0}^{\infty} 4 \pi r^{2} \gamma_{0}(r) \frac{\sin (Q r)}{Q r} \mathrm{~d} r=n_{\mathrm{P}}\lfloor\Delta \rho\rfloor^{2} V_{\mathrm{P}}^{2} F_{\mathrm{P}}^{2}(Q) S_{\mathrm{P}}(Q)
$$




\subsection{Determination of the volume fractions using the scattering invariant}

The volume fraction of a given set of scattering features is determined using the scattering invariant. The scattering invariant is obtained by integrating the small angle scattering intensity over all $Q$ [23]. The volume fraction, $\Phi_{v}$ and the scattering invariant are related using the following expression.

$$
\text { Scattering invariant }=2 \pi^{2} \Phi_{\mathrm{v}}\left(1-\Phi_{\mathrm{v}}\right)|\Delta \rho|^{2}=\int_{0}^{\infty} Q^{2} \frac{\mathrm{d} \Sigma}{\mathrm{d} \Omega}(Q) \mathrm{d} Q
$$

\subsection{Determination of the mean volumes and radius of gyration using the guinier approximation}

The mean radius of gyration of narrowly dispersed and uncorrelated scattering features is determined using the Guinier approximation. The following expression relates the scattering intensity, $I(Q)$ to the mean radius of gyration, $R_{\mathrm{G}^{\prime}}$ particle volume, $\mathrm{V}_{\mathrm{P}^{\prime}}$ the scattering contrast factor, $|\Delta \rho|^{2}$ and the volume fraction, $\Phi_{\mathrm{v}}$

$$
I(Q)=\frac{d \Sigma}{d \Omega}=\Phi_{\mathrm{V}}|\Delta \rho|^{2} V_{\mathrm{P}} \exp \left(-\frac{Q^{2} R_{\mathrm{G}}^{2}}{3}\right)
$$

\subsection{Determination of the morphology or roughness of solid interfaces from the porod scattering regime}

The Porod region is used to probe the local structure at the higher $q$ regimes. In porous materials, the relative roughness or smoothness of the pore-solid interface is quantified using the Porod slope [25]. The Porod slope is determined using the following relationships where $I(Q)$ and $n$ represent the scattering intensity and the slope, respectively:

$$
\begin{gathered}
I(Q)=\frac{A}{Q^{n}}+B \\
\log _{10}[I(Q)-B]=\log _{10} A-n \log _{10} Q
\end{gathered}
$$

Scattering from rigid rods provides a Porod slope of 1 . Porod slopes between 2 and 3 represent branched systems or networks also known as mass fractals. Porod slopes between 3 and 4 represent rough interfaces with a fractal dimension, $D$ where $n=6-D$ and $n$ represents a surface fractal. A smooth surface has a Porod slope of 4 . For a smooth surface, the surface area, $S_{v}$ can be directly related to the scattering intensity, $I(Q)$ and the flat background scattering, bg using the following expression.

$$
I(Q)=\frac{2 \pi|\Delta \rho|^{2} S_{v}}{Q^{4}}+b g
$$

\subsection{Shapes and size distributions}

One of the challenges with USAXS and SAXS is the need for microstructural insights prior to the morphological quantification of a material. Information needed a priori includes insights 
into the polydispersity of the scatterers and shape features such as disks, sheets, laminar structures, cylinders, rods, or capillary pores, core-shell particles [22, 23], and spheres [26, 27]. Once the shape of the features is known, the size distributions can be determined by optimizing the scattering intensity from a predefined set of histogram bin sizes also known as the entropy maximization technique, using a least-squares fitting Fourier Transform method, or fitting a functional form of the size distribution and averaging the scattering over the chosen size distribution function. Homogeneous systems can be fitted using a single functional form. The morphologies of hierarchical materials, on the other hand, are better fitted by binning the scattering intensities corresponding to various sizes. Some of the challenges with this approach include the need for multiple iterations for model convergence and the generation of multiple fitting parameters [28, 29].

\section{Brief description of USAXS/SAXS instrumentation}

The ability to obtain a wide $Q$ range that spans four decades in spatial resolution from $10^{-4}$ to $1 \AA^{-1}$ is attributed to the application of Bonse-Hart crystal optics. The flexible geometry, crystal optics independent of the sample apertures, source, and size of the point detector conferred by Bonse Hart crystals allow for the detection of a wide $Q$ range. The constituents of a typical Bonse-Hart USAXS instrument include a pair of collimating crystals, ion chamber, guard slits, analyzer crystals, and a photodiode detector. In order to obtain a monochromatic beam, the pre-monochromated beam is passed through the 2-D slits and a pair of collimating crystals set to the angle satisfying the Bragg condition. The X-rays scattered by the sample are then passed through the analyzer crystals and the intensity is measured by the point detector.

\section{Morphological and structural changes in beidellite on heating}

\subsection{Materials and methods}

Beidellite procured from The Source Clay Mineral Repositories (Purdue University, West Lafayette, IN) are ground to a size smaller than $75 \mu \mathrm{m}$ and compacted into a pellet with a thickness of about $0.5 \mathrm{~mm}$. The pellet is placed in a Linkam TS1500 heating stage (Linkam Scientific Instruments Ltd., Tadworth, UK) in alignment with the synchrotron beamline. The starting and final temperatures of $30^{\circ} \mathrm{C}$ and $1150^{\circ} \mathrm{C}$ are set with a temperature ramp rate of $3^{\circ} \mathrm{C} / \mathrm{min}$. The X-ray scattering measurements are performed at the USAXS instrument at sector 9-ID at the Advanced Photon Source (APS), Argonne National Laboratory, Argonne, IL. Using this instrument, USAXS measurements are combined with pinhole-camera based SAXS measurements and with WAXS measurements. The USAXS, SAXS and WAXS data are represented as a function of the scattering or diffracted intensity, $I(q)$ versus $q$ where $q=(4 \pi / \lambda)$ $\sin \theta$ (and $q=(2 \pi / d)$ to determine a lattice spacing, $d$, from an XRD peak in the WAXS data), $\lambda$ is the X-ray wavelength and $\theta$ is half of the scattering or diffracted angle, 2 $\theta$. Data collection times for USAXS, SAXS and WAXS are 90, 30, and 30, respectively, for a total of $\approx 3$ min, including time for instrument stage motions. The sample configuration within the beam is not changed and the measurements are made within a few minutes of each other. The beam size 
settings of $(0.8 \times 0.8) \mathrm{mm}$ for USAXS and $(0.8 \times 0.2) \mathrm{mm}$ for SAXS (pinhole SAXS or pin-SAXS) and WAXS are used. The sample-to-detector distances for SAXS and WAXS are set to $547 \mathrm{~mm}$ and $181 \mathrm{~mm}$, respectively. The X-ray energy is to $21.0 \mathrm{keV}$. The total X-ray flux at the sample is $\approx 10^{13}$ photon $\mathrm{s}^{-1}$. Silver behenate and NIST standard reference material, SRM 660c $\left(\mathrm{LaB}_{6}\right)$ are used for the calibration of $q$ values and sample-to-detector distances. The collected data are reduced and analyzed using the Irena [31] and Nika [32] software packages written in IgorPro (Wavemetrics, Lake Oswego, OR).

\subsection{Structural changes in beidellite on heating}

One of the interesting structural features in clays is the hierarchical arrangement of the nanosheets and the characteristic interlayer basal distances. The interlayer water confined between the nanosheets contributes to the swelling behavior of these materials. In case of beidellite, a swelling clay, the characteristic interlayer basal spacing decreased from 12.5 to $9.7 \AA$ on heating from 32 to $308^{\circ} \mathrm{C}$ (Figure 2). This reduction in the interlayer basal distance corresponds to the removal of the one layer of interlayer water. A progressive reduction in the intensity of the peak corresponding to the interlayer basal distance of beidellite is also noted on heating to $1150^{\circ} \mathrm{C}$. The decreasing peak intensity on heating suggests a reduction in the number of interlayer nanopores on heating. On the structural front, a significant reduction in the intensity of the characteristic beidellite peak that corresponds to $q=4.22 \AA^{-1}, d=1.49 \AA$ (h k 1: $\left(\begin{array}{lll}0 & 6 & 0\end{array}\right),\left(\begin{array}{lll}3 & 3 & 0\end{array}\right)$ ) [21] is noted (Figure 3). The trend in the reduction of the peak intensity of beidellite on heating is similar to that of Na- and Ca-montmorillonite reported in previous studies [17]. It was interesting to note the onset of significant structural changes in beidellite (Figure 3) after a reduction in the interlayer basal distance (Figure 2).
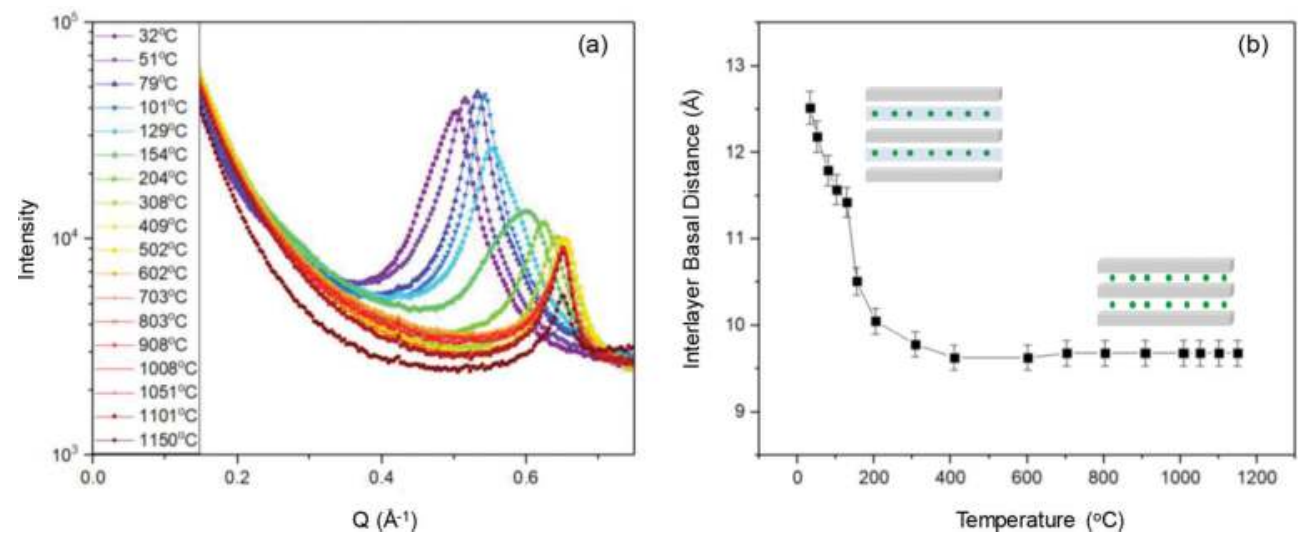

Figure 2. Changes in the characteristic peak corresponding to the interlayer basal distance $(d(001)$ peak) in beidellite (a) and the corresponding d-spacing (b) on heating from 30 to $1150^{\circ} \mathrm{C}$. Vertical bars are standard deviation uncertainties obtained from the peak profile fitting. 


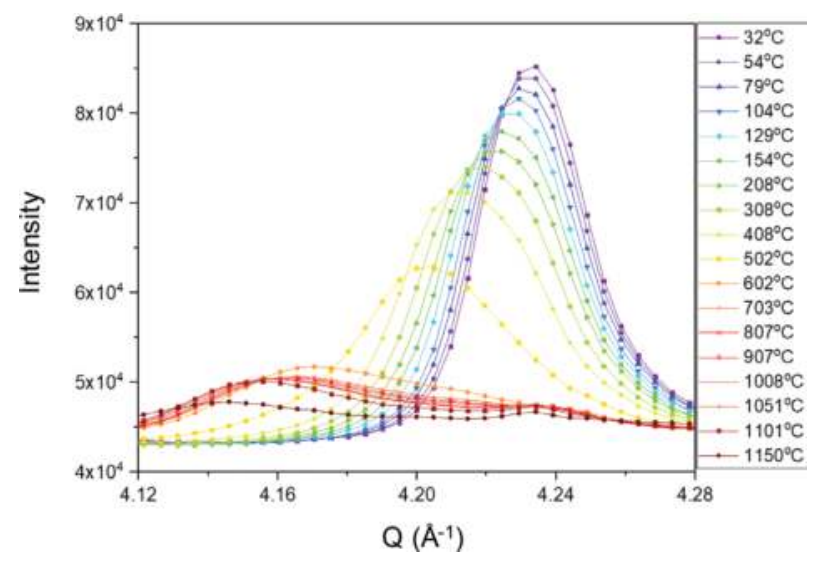

Figure 3. Changes in the characteristic beidellite peak $\left(q=4.22 \AA^{-1}, d=1.49 \AA, h k l: 060,330\right)[21]$ on heating to $1150^{\circ} \mathrm{C}$.

\subsection{Morphological changes in beidellite on heating}

The USAXS and SAXS data are collected in the range $\left(10^{-4}\right.$ to 1.5$) \AA^{-1}$ (Figure 4(a)). As the temperature is increased from 32 to $1150^{\circ} \mathrm{C}$, the scattering intensity increased 43,58 , and $25 \%$ at $Q=0.1,0.001$, and $0.0001 \AA^{-1}$, respectively. While changes in the scattering contrast are noted, significant changes in the shape of the scattering curve are not evident. Another consideration is the extent of reversibility in the morphological changes in beidellite. As discussed in the previous section, the changes in the interlayer basal distance coupled with the structural changes in beidellite produce irreversible morphological changes in beidellite.

To quantify the morphologies in beidellite on heating, the scattering contrast factor, $|\Delta \rho|^{2}$ is applied. The scattering contrast factor is the square of the difference in the scattering length
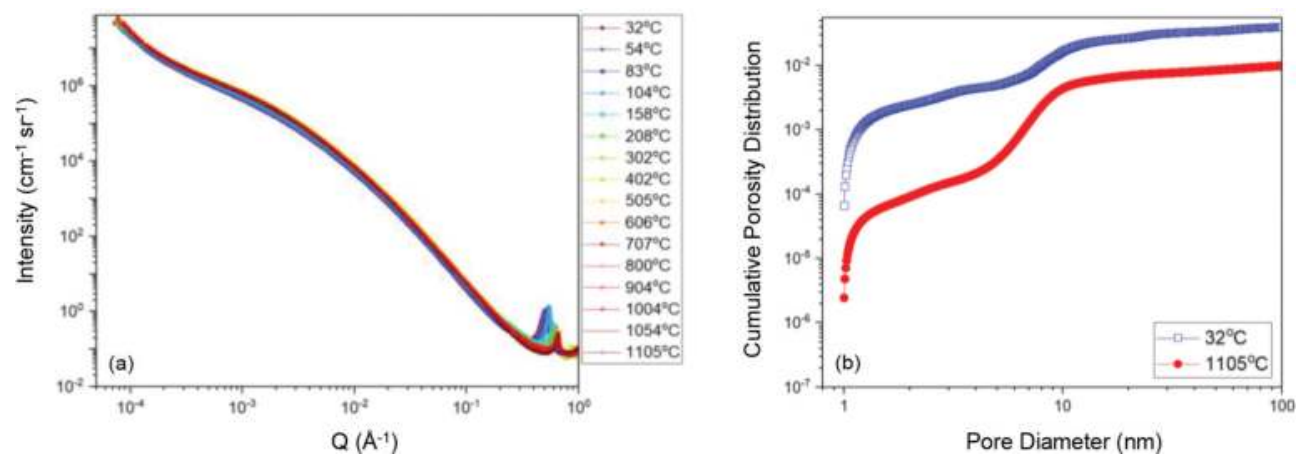

Figure 4. Changes in the combined slit-smeared USAXS/SAXS data for beidellite on heating in temperature ranges of $32-1105^{\circ} \mathrm{C}(\mathrm{a})$ and the cumulative pore volume distributions at $32^{\circ} \mathrm{C}$ and $1105^{\circ} \mathrm{C}(\mathrm{b})$. 
density (SLD or $\rho$ ) between the two phases. The scattering length density is a function of the chemical composition and density of the phase. In case of beidellite, the scattering contrast factor at the beginning of the experiment emerges from the contrast between the solid and interlayer water. This scattering contrast factor is determined to be $100 \times 10^{28} \mathrm{~m}^{-4}$. On heating to $1105^{\circ} \mathrm{C}$, the beidellite structure undergoes significant structural changes as evident in Figure 3. The loss of water and densification of the material increase the scattering contrast factor to $500 \times 10^{28} \mathrm{~m}^{-4}$.

To quantify the changes in the morphology of beidellite, the void size distributions are modeled as spheroids with an aspect ratio of 0.2 , which allows us to account for the layered morphology of clays. The size distributions are determined using the entropy maximization routine, MaxEnt $[28,30]$. These results are shown in Figure $4(\mathbf{b})$. On heating to $1105^{\circ} \mathrm{C}$, the porosity in the range of $1-10 \mathrm{~nm}$ is reduced by nearly two orders of magnitude. These results are consistent with the reduction in the intensity of the interlayer basal distance corresponding to the porosity between the clay nanosheets as shown in Figure 2. This example illustrates one approach to quantify the changes in the nanoscale porosity corresponding to the interlayer basal spacing using USAXS measurements, the interlayer basal spacing in the SAXS regime, and the structure in the beidellite nanosheet in the WAXS regime in a single measurement.

\section{Morphological and structural changes in heat-treated serpentine on carbon mineralization}

One of the approaches for permanent carbon storage is to use highly reactive Ca- and $\mathrm{Mg}$-bearing substrates that can react with $\mathrm{CO}_{2}$ to form thermodynamically stable and environmentally benign calcium or magnesium carbonates [33-37]. Examples of reactive Caand $\mathrm{Mg}$-bearing materials include wollastonite $\left(\mathrm{CaSiO}_{3}\right)$, olivine $\left(\mathrm{Mg}_{2} \mathrm{SiO}_{4}\right)$, and serpentine $\left(\mathrm{Mg}_{3} \mathrm{Si}_{2} \mathrm{O}_{5}(\mathrm{OH})_{4}\right)$. Serpentine is widely mined for extracting nickel and the use of serpentine mine tailings for accelerated carbon mineralization has been proposed [38]. However, the kinetics of $\mathrm{CO}_{2}$ interactions with serpentine are slow. To accelerate these kinetic interactions, the heat treatment of serpentine is proposed. Heat treating serpentine to temperatures of $625^{\circ} \mathrm{C}$ dehydroxylates the lattice enabling its conversion to an amorphous state [39]. This amorphous material has a higher reactivity with $\mathrm{CO}_{2}$ compared to the unreacted material. Recent studies have shown that heat-treated serpentine is effective in capturing and converting $\mathrm{CO}_{2}$ from flue gas streams to magnesium carbonate [40]. However, the change in the pore size as the heat-treated serpentine is converted to magnesite is not well understood.

A reduction in the porosity of heat-treated serpentine as it is converted to magnesite may potentially limit the reactivity of the material by preventing the migration of $\mathrm{Mg}$. In this context, quantification of the extent of reduction in the porosity of heat-treated serpentine on conversion to magnesium carbonate is useful. Combined ultrasmall, small, and wide angle X-ray scattering (USAXS/SAXS/WAXS) is particularly useful in linking changes in the porosity of heat-treated serpentine to the formation of magnesite. In this study, serpentine was heat-treated to $625^{\circ} \mathrm{C}$ and the resulting material was reacted at $185^{\circ} \mathrm{C}, \mathrm{P}_{\mathrm{CO} 2}=139$ bar in $1.0 \mathrm{M} \mathrm{NaCl}$ and $0.64 \mathrm{M} \mathrm{NaHCO}_{3}$ 


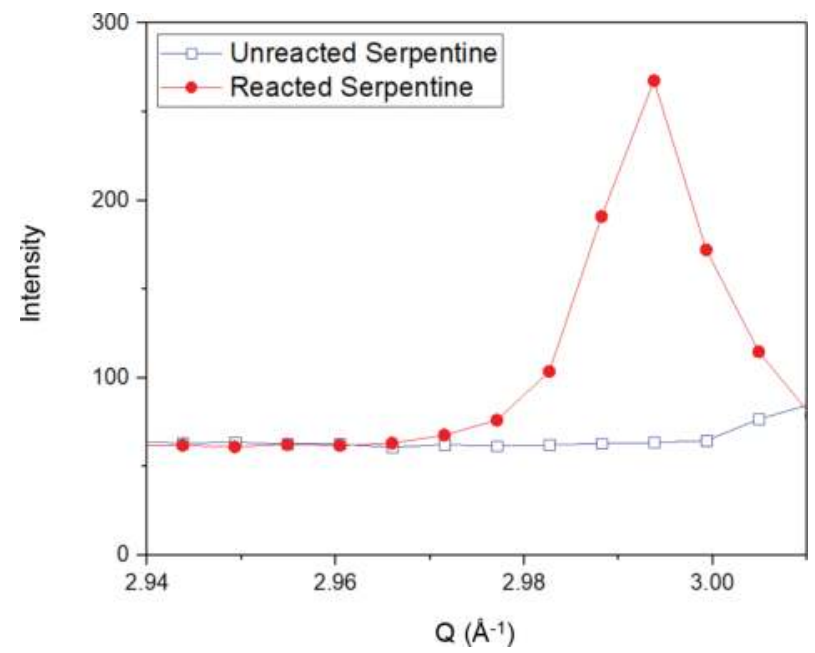

Figure 5. Evidence of the formation of magnesite on the carbon mineralization of heat-treated serpentine $\left(q=2.99 \AA^{-1}\right.$, $d=2.10 \AA$, hkl: 113) [41] on heating to $1150^{\circ} \mathrm{C}$.

for $3 \mathrm{~h}$ while stirring at $300 \mathrm{rpm}$ in a pressurized batch process. The extent of carbonation of heat-treated serpentine to magnesium carbonate is $48 \%$. The particle sizes of these materials before and after carbon mineralization were determined to be in the range of 3-100 $\mu \mathrm{m}$.

WAXS measurements of the heat-treated serpentine before and after the carbonation reaction showed the formation of magnesite. The characteristic magnesite peak corresponding to $q=2.99 \AA^{-1}, d=2.10 \AA$ and $h k l: 113$ is shown in Figure 5. At the lower $Q$ regions, a reduction in the scattering intensity is noted (Figure 6(a)). The scattering contrast factors are applied to determine changes in the morphology of the materials. The scattering contrast factor of the
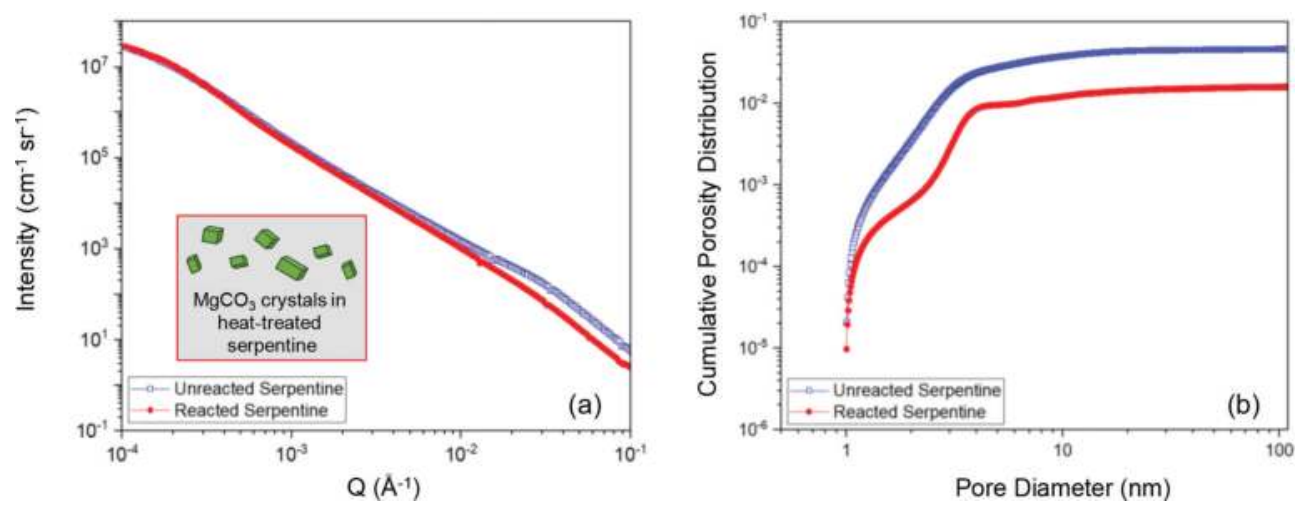

Figure 6. Changes in combined slit-smeared USAXS/SAXS data of heat treated serpentine to form magnesium carbonate (a) and the reduction in the porosity as determined from the scattering data (b). 
unreacted and reacted heat-treated serpentine are $446 \times 10^{28} \mathrm{~m}^{-4}$ and $574 \times 10^{28} \mathrm{~m}^{-4}$, respectively. The scattering contrast factors and the void size distributions with an aspect ratio of 1 are the important inputs to determine the morphological changes in these materials using the entropy maximization routine, MaxEnt $[28,30]$. The changes in the cumulative pore volume distributions of heat-treated serpentine before and after carbon mineralization are shown in Figure 6(b). A significant reduction in the void spaces corresponding to sizes in the range of $2-6 \mathrm{~nm}$ is noted. These findings are consistent with the previous observations of reduced porosity due to magnesite growth on olivine grains [35].

\section{Conclusions}

In this chapter, we have illustrated the use of combined USAXS, SAXS, and WAXS measurements to quantify reaction-driven microstructural and structural changes involving complex architected and natural materials. These materials include beidellite, a swelling clay from the smectite family of minerals, and serpentine, a layered sheet silicate that belongs to the family of phyllosilicates. The combined USAXS, SAXS, and WAXS techniques available at Sector 9-ID at the Advanced Photon Source in Argonne National Laboratory allows for measurements that span nearly four decades in spatial scale. This chapter also illustrates the need for prior knowledge about the morphological arrangement in materials to quantify the key features such as the changes in the porosity or surface area of porous materials on reaction. In this context, recent advancements in electron microscopy and X-ray tomography have aided the quantitative interpretation of the $X$-ray scattering measurements discussed in this chapter.

\section{Acknowledgements}

The author gratefully acknowledges the Wisconsin Alumni Research Foundation and the College of Engineering at the University of Wisconsin, Madison. A special thanks to Dr. Jan Ilavsky and Dr. Ivan Kuzmenko, X-ray Science Division, Argonne National Laboratory, for providing experimental support for the combined USAXS/SAXS/WAXS measurements at the Advanced Photon Source. The use of the Advanced Photon Source, an Office of Science User Facility operated for the U.S. Department of Energy (DOE) Office of Science by Argonne National Laboratory, is supported by the U.S. DOE under Contract DE-AC02-06CH11357.

\section{Author details}

\section{Greeshma Gadikota}

Address all correspondence to: gadikota@wisc.edu

Department of Civil and Environmental Engineering, Environmental Chemistry and Technology Program, Geological Engineering Program, Grainger Institute for Engineering, University of Wisconsin, Madison, USA 


\section{References}

[1] Freelon B, Suthar K, Ilavsky J. A multi-length-scale USAXS/SAXS facility: 10-50 keV small-angle X-ray scattering instrument. Journal of Applied Crystallography. 2013; 46(5):1508-1512

[2] Reich MH, Russo SP, Snook IK, Wagenfeld HK. The application of SAXS to determine the fractal properties of porous carbon-based materials. Journal of Colloid and Interface Science. 1990;135(2):353-362

[3] Radlinski AP, Radlinska EZ. The microstructure of pore space in coals of different rank. In: Coalbed Methane: Scientific, Environmental and Economic Evaluation. Springer Netherlands; 1999. pp. 329-365

[4] Radlinski AP, Mastalerz M, Hinde AL, Hainbuchner M, Rauch H, Baron M, Lin JS, Fan L, Thiyagarajan P. Application of SAXS and SANS in evaluation of porosity, pore size distribution and surface area of coal. International Journal of Coal Geology. 2004;59(3):245-271

[5] McMahon PJ, Snook IK, Treimer W. The pore structure in processed Victorian brown coal. Journal of Colloid and Interface Science. 2002;252(1):177-183

[6] Prinz D, Pyckhout-Hintzen W, Littke R. Development of the meso-and macroporous structure of coals with rank as analysed with small angle neutron scattering and adsorption experiments. Fuel. 2004;83(4):547-556

[7] Bale HD, Schmidt PW. Small-angle X-ray-scattering investigation of submicroscopic porosity with fractal properties. Physical Review Letters. 1984;53(6):596

[8] Cohen MH. The morphology of porous sedimentary rocks. Physics and Chemistry of Porous Media-II. 1987;154(1):3-16

[9] Lucido G, Triolo R, Caponetti E. Fractal approach in petrology: Small-angle neutron scattering experiments with volcanic rocks. Physical Review B. 1988;38(13):9031

[10] Floriano MA, Venezia AM, Deganello G, Svensson EC, Root JH. The structure of pumice by neutron diffraction. Journal of Applied Crystallography. 1994;27(3):271-277

[11] Kahle A, Winkler B, Radulescu A, Schreuer J. Small-angle neutron scattering study of volcanic rocks. European Journal of Mineralogy. 2004;16(3):407-417

[12] Anovitz LM, Lynn GW, Cole DR, Rother G, Allard LF, Hamilton WA, Porcar L, Kim $\mathrm{MH}$. A new approach to quantification of metamorphism using ultra-small and small angle neutron scattering. Geochimica et Cosmochimica Acta. 2009;73(24):7303-7324

[13] Anovitz LM, Cole DR, Rother G, Allard LF, Jackson AJ, Littrell KC. Diagenetic changes in macro-to nano-scale porosity in the St. Peter sandstone: An (ultra) small angle neutron scattering and backscattered electron imaging analysis. Geochimica et Cosmochimica Acta. 2013;102:280-305 
[14] Gu X, Cole DR, Rother G, Mildner DF, Brantley SL. Pores in marcellus shale: A neutron scattering and FIB-SEM study. Energy \& Fuels. 2015;29(3):1295-1308

[15] Bahadur J, Radlinski AP, Melnichenko YB, Mastalerz M, Schimmelmann A. Small-angle and ultrasmall-angle neutron scattering (SANS/USANS) study of New Albany shale: A treatise on microporosity. Energy \& Fuels. 2015;29(2):567-576

[16] Lee S, Fischer TB, Stokes MR, Klingler RJ, Ilavsky J, McCarty DK, Wigand MO, Derkowski A, Winans RE. Dehydration effect on the pore size, porosity, and fractal parameters of shale rocks: Ultrasmall-angle X-ray scattering study. Energy \& Fuels. 2014; 28(11):6772-6779

[17] Gadikota G, Zhang F, Allen AJ. Towards understanding the microstructural and structural changes in natural hierarchical materials for energy recovery: In-operando multi-scale X-ray scattering characterization of Na- and Ca-montmorillonite on heating to $1150{ }^{\circ} \mathrm{C}$. Fuel. 2017;196:195-209

[18] Gadikota G, Zhang F, Allen A. In-situ angstrom-to-micrometer characterization of the structural and microstructural changes in kaolinite on heating using ultrasmall-angle, smallangle, and wide-angle X-ray scattering (USAXS/SAXS/WAXS). Industrial \& Engineering Chemistry Research. 2017;56(41):11791-11801

[19] Gadikota G, Allen AJ. Microstructural and structural characterization of materials for $\mathrm{CO}_{2}$ storage using multi-scale scattering methods. In: Li L, Wong-Ng W, editors. Materials and Processes for $\mathrm{CO}_{2}$ Capture, Conversion, and Sequestration. Hoboken, NJ: Wiley Books; 2018

[20] De Stefanis A, Tomlinson AAG. Towards designing pillared clays for catalysis. Catalysis Today. 2006;114(2-3):126-141

[21] Weir AH, Greene-Kelly R. Beidellite. American Mineralogist. 1962;47:137-146

[22] Fournet G, Guinier A. Small Angle Scattering of X-Rays. New York: John Wiley \& Sons; 1955

[23] Glatter O, Kratky O. Small angle scattering. New York: Academic; 1982

[24] Warren BE. X-Ray Diffraction. New York: Dover; 1990

[25] Porod G. X-ray low angle scattering of dense colloid systems, part II. Kolloid Zeitschrift. 1952;125:108-122

[26] Roess LC, Shull CG. X-ray scattering at small angles by finely-divided solids. II. Exact theory for random distributions of spheroidal particles. Journal of Applied Physics. 1947;18(3):308-313

[27] Shull CG, Roess LC. X-ray scattering at small angles by finely-divided solids. I. General approximate theory and applications. Journal of Applied Physics. 1947;18(3):295-307

[28] Potton JA, Daniell GJ, Rainford BD. Particle size distributions from SANS data using the maximum entropy method. Journal of Applied Crystallography. 1988;21(6):663-668 
[29] Morrison JD, Corcoran JD, Lewis KE. The determination of particle size distributions in small-angle scattering using the maximum-entropy method. Journal of Applied Crystallography. 1992;25(4):504-513

[30] Potton JA, Daniell GJ, Eastop AD, Kitching M, Melville D, Poslad S, Rainford BD, Stanley H. Ferrofluid particle size distributions from magnetisation and small angle neutron scattering data. Journal of Magnetism and Magnetic Materials. 1983;39:95-98

[31] Ilavsky J, Jemian PR. Irena: Tool suite for modeling and analysis of small-angle scattering. Journal of Applied Crystallography. 2009;42(2):347-353

[32] Ilavsky J. Nika: Software for two-dimensional data reduction. Journal of Applied Crystallography. 2012;45(2):324-328

[33] Gadikota G, Natali C, Boschi C, Park AHA. Morphological changes during enhanced carbonation of asbestos containing material and its comparison to magnesium silicate minerals. Journal of Hazardous Materials. 2014;264:42-52

[34] Gadikota G, Swanson EJ, Zhao H, Park A-HA. Experimental design and data analysis for accurate estimation of reaction kinetics and conversion for carbon mineralization. Industrial and Engineering Chemistry Research. 2014;53(16):6664-6676

[35] Gadikota G, Matter J, Kelemen P, Park A-HA. Chemical and morphological changes during olivine carbonation for $\mathrm{CO}_{2}$ storage in the presence of $\mathrm{NaCl}$ and $\mathrm{NaHCO}_{3}$. Physical Chemistry Chemical Physics. 2014;16(10):4679-4693

[36] Gadikota G, Fricker K, Jang S-H, Park A-HA. Carbonated silicate minerals and industrial wastes as construction materials. In: Advances in $\mathrm{CO}_{2}$ Capture, Sequestration, and Conversion. Washington, DC: American Chemical Society; 2015. pp. 295-322

[37] Lackner KS. Carbonate chemistry for sequestering fossil carbon. Annual Review of Energy and the Environment. 2002;27(1):193-232

[38] Wilson SA, Raudsepp M, Dipple GM. Verifying and quantifying carbon fixation in minerals from serpentine-rich mine tailings using the Rietveld method with X-ray powder diffraction data. American Mineralogist. 2006;91(8-9):1331-1341

[39] McKelvy MJ, Chizmeshya AVG, Diefenbacher J, Béarat H, Wolf G. Exploration of the role of heat activation in enhancing serpentine carbon sequestration reactions. Environmental Science \& Technology. 2004;38(24):6897-6903

[40] Werner M, Hariharan S, Mazzotti M. Flue gas $\mathrm{CO}_{2}$ mineralization using thermally activated serpentine: From single-to double-step carbonation. Physical Chemistry Chemical Physics. 2014;16(45):24978-24993

[41] Brown G, Brindley GW. Crystal Structures of Clay Minerals and their X-Ray Identification. London: Mineralogical Society; 1980 
